\title{
A CIDADANIA COMO PERTENCIMENTO: UMA REFLEXÃO A PARTIR DA PSICANÁLISE
}

\author{
CITIZENSHIP AS BELONGING: A REFLECTION FROM PSYCHOANALYSIS
}

Carlos Alberto Plastino ${ }^{1}$

Resumo $\mathrm{O}$ artigo discute o trabalho de Adriana Geisler sobre a educação politécnica focando as questões referidas à emergência da subjetividade. Defendendo a perspectiva que concebe o processo de subjetivação como indissociável da inserção social, critica o conceito de indivíduo, propondo sua substituição pelo conceito de singularidade do sujeito. Utilizando as ferramentas teóricas elaboradas pela teoria psicanalítica, o artigo mostra os limites do pensamento de Freud nas questões vinculadas à concepção do indivíduo e de suas relações com a sociedade, expondo sumariamente a elaboração de D. Winnicott que, neste ponto, procede a uma revisão radical da teoria freudiana.

Palavras-chave indivíduo, singularidade, paradigma, ambiente.

Abstract The article discusses the work of Adriana Geisler on polytechnic education focusing the questions referred to the emergency of subjective. Defending the perspective that conceives the process of subjectivation as undissociable from the social insertion, she criticizes the concept of the individual, proposing its replacement by the concept of the uniqueness of the subject. Using the theoretical tools elaborated by the psychoanalytic theory, the article shows the limits of Freud's thought on the questions linked to the conception of the individual and his relations with society, concisely exposing the elaboration of D. Winnicott that, in this point, proceeds to a radical review of the Freudian theory.

Key words individual, singularity, paradigm, environment 


\section{A cidadania como pertencimento: uma reflexão a partir da psicanálise}

Inserindo a problemática da educação politécnica no contexto de uma compreensão coletiva e emancipatória da cidadania - cidadania como pertencimento -, Adriana Geisler se impôs uma tarefa ambiciosa. Para levá-la a bom termo, teve que articular a significação dos movimentos sociais da década de 1980 com uma substantiva discussão histórico-conceitual sobre a emergência do conceito de cidadania na modernidade ocidental e seu relacionamento com o surgimento do capitalismo. Minha colaboração consistirá em desenvolver, a partir da minha própria perspectiva de trabalho, algumas questões que, constituindo o pano de fundo de sua reflexão, não puderam ser desenvolvidas, mas apenas indicadas no seu texto.

As questões a que pretendo me referir são introduzidas no trabalho da autora através de duas afirmações polêmicas. A primeira se refere à precedência do sujeito em relação à sociedade; a segunda, em sentido contrário, à concepção da emergência do sujeito como indissociável de sua inserção social. A autora adota corretamente, a meu ver, a segunda alternativa, afirmando que a constituição do sujeito e a sua inserção na cultura constituem um único e mesmo processo.

Esta posição é polêmica, na medida em que colide com um dos pressupostos fundamentais do imaginário moderno, o 'individualismo'. A afirmação da autora exige, assim, ser discutida em todas as implicações, o que significa, creio, introduzir no debate a concepção do 'cenário' no qual se opera a emergência do sujeito. Esse cenário se organiza em torno das relações entre a natureza e a cultura, questão sobre a qual o imaginário moderno sustenta uma posição questionada pela perspectiva adotada pela autora.

O imaginário moderno construiu seu paradigma ${ }^{2}$ em torno de uma perspectiva dualista, cuja matriz é a separação do ser humano em relação à natureza. Essa perspectiva se desdobra, ainda, no dualismo, na concepção do próprio homem, entre seu psiquismo - reduzido à consciência racional - e seu corpo, assimilado a uma máquina, fonte de 'forças' alheias a qualquer sentido. Desdobra-se também no dualismo constitutivo do processo de conhecimento, que, separando o sujeito do objeto, sanciona a exclusividade do conhecimento científico-racional. Este conjunto de pressupostos se associa à concepção do sujeito enquanto 'indivíduo' que antecede a sociedade e cuja inserção nesta constitui um fato que é preciso justificar.

Tal concepção, hegemônica no imaginário moderno, estreita as alternativas para se conceber as relações entre o indivíduo e a sociedade, estabelecendo o que Adriana Geisler denomina "oposição maniqueísta". Em uma das alternativas, o desejo do indivíduo é considerado libertador, enquanto a sociedade só pode ser pensada como repressora. Na outra alternativa, o 
desejo individual, em que predomina o desejo de agredir e matar, segundo Hobbes e Freud, ocupa o pólo do mal nessa equação maniqueísta, sendo atribuído à repressão exercida pela sociedade o caráter de necessidade, tendo em vista a exigência de sua própria sobrevivência. Percebe-se então que, nas perspectivas imagináveis no território delimitado pelos pressupostos do paradigma moderno, o sujeito só pode ser 'salvo' demonizando a sociedade, ou, alternativamente, o sujeito é ele mesmo demonizado, privilegiando-se, na consideração da sociedade, suas funções repressivas.

A ultrapassagem destas alternativas supõe questionar a matriz que as gera, o que significa criticar os pressupostos paradigmáticos da modernidade no que se refere ao homem, à natureza e às modalidades de seus relacionamentos. Esta crítica permitirá pensar o sujeito incorporando todos os ganhos produzidos a partir do conceito de indivíduo - direitos individuais invioláveis -, modificando, entretanto, a maneira de pensar sua relação com a sociedade. O conceito de 'singularidade', em substituição ao de individualidade, exprime essa ampliação fundamental de perspectiva.

A produção do conceito de singularidade do sujeito, isto é, de seu radical pertencimento a si mesmo sem abdicar de seu pertencimento à sociedade $^{3}$, requer pensar o homem de uma maneira radicalmente diferente da permitida pela ótica cartesiana. Supõe, com efeito, superar tanto o dualismo que separa o corpo do psiquismo, quanto o maquinismo que reduz o corpo à sede de forças consideradas como quantidades e, ainda, a concepção do psiquismo reduzida à consciência racional. Exige também ultrapassar o monopólio concedido à razão nos processos de conhecimento. Este processo é fundamental para, em consonância com a complexidade da vida, do homem e da sociedade, incorporar a complexidade de formas de saber, admitindo aquelas que, embora não adotem os métodos da ciência positiva, produzem um saber pertinente.

A obra teórica de Freud se relaciona com as questões sintetizadas no parágrafo anterior de maneira complexa. De um lado, a afirmação do psiquismo inconsciente e de suas capacidades - registro, percepção, apreensão de sentido, imaginação -, bem como as características do saber por ele fundado - a psicanálise ${ }^{4-}$, caracterizam uma frontal contestação às concepções do paradigma sobre o homem e sobre o processo de conhecimento. No mesmo sentido, opera a descoberta do papel central da afetividade humana nos processos de produção e apreensão de sentido. Por outro lado, a manutenção de uma concepção determinista da natureza, bem como de uma concepção hobbesiana do indivíduo e suas relações com a sociedade, aprisionam seu pensamento nos estreitos limites traçados pela concepção moderna. Sua conhecida tese sobre o caráter inevitável do sentimento de culpa e do mal-estar na vida cultural (seu pessimismo) deriva, também ela, da permanência de pressupostos do paradigma moder- 
no na sua concepção teórica. Vejamos mais detalhadamente estas diversas facetas do pensamento freudiano.

O afastamento progressivo e incompleto da produção teórica de Freud dos pressupostos centrais do paradigma moderno não impediu que tais pressupostos tivessem forte influência na elaboração inicial da metapsicologia5. Alguns deles, como já foi dito, foram mantidos por Freud ao longo de toda sua obra, embora suas próprias descobertas e os conceitos teóricos elaborados a partir delas colidissem com eles. Cabe sublinhar, em especial, a adesão de Freud à perspectiva segundo a qual a modernidade pensou a relação entre o ser humano e a natureza. Separando um do outro, essa perspectiva concebeu a relação entre ambos como uma prática de dominação. Inserindose numa longa tradição, Freud pensa aquilo que no homem é natural (corpo, pulsões, paixões) como algo que é preciso controlar - e reprimir - para tornar possível a vida social.

É notável que seja precisamente no último período de sua formulação teórica, quando, em diversas questões importantes, mais se afasta da perspectiva da modernidade, que sua adesão à oposição entre sociedade e indivíduo se torne mais explícita e contundente. É o que se exprime na sua segunda teoria pulsional, segundo a qual o homem é movido por duas pulsões elementares e imodificáveis ${ }^{6}$; uma das quais - a pulsão de morte - nutre um indomável impulso de agressão. Essa agressão, segundo Freud, é controlada pela sociedade por meio da introjeção, no psiquismo de cada sujeito, de uma instância - o superego - que contém as proibições e injunções da cultura, em especial a proibição da agressão, do assassinato e da prática do incesto. Na ótica freudiana, a consciência moral é assim introduzida em cada sujeito pela repressão operada na cultura, não sendo um conteúdo do ego, mas do superego. Sua energia é a própria energia da agressão, sendo que a renúncia a essa pulsão agressiva imposta pelo superego alimenta a agressão que o próprio superego exerce contra o ego. Desse modo, pensa Freud, a introjeção do superego permite reenviar a agressão a seu ponto de origem, isto é, dirigi-la contra o ego. Este processo sustenta a universalidade do sentimento de culpa e o inevitável mal-estar cultural.

Repare-se que todo este processo se apóia na postulação de uma ambivalência afetiva originária 7 , pela qual o outro é, simultânea e indissociavelmente, objeto de amor e de ódio. O mal-estar insuperável do sujeito na vida social emerge, assim, do desamparo que ele experimenta tanto do ponto de vista de sua prolongada dependência inicial do outro para sobreviver, quanto do impacto da pulsão de morte da qual é portador. A primeira fonte, a dependência, faz com que o indivíduo renuncie ao impulso de agressão de maneira a obter a proteção e aprovação do outro de quem depende, estando assim na origem do processo gerador da instância superegóica. A segunda fonte, o impacto da pulsão de morte, também insuperável, nutre a permanência e a expansão do sentimento de culpa. 
Esta oposição conflituosa entre o indivíduo e a sociedade, sustenta-se, inequivocamente, numa perspectiva individualista que pensa não a constituição do sujeito, mas seu funcionamento no processo de socialização. Adere, implicitamente, à perspectiva moderna, segundo a qual o indivíduo precede a sociedade, diferenciando, assim, os processos de constituição da subjetividade e de socialização.

É importante salientar, entretanto, que o próprio Freud teorizou processos através dos quais a constituição do sujeito foi concebida no bojo da relação com o outro. É o caso da identificação primária - direta e não mediada, processada por via puramente afetiva - e também das posteriores identificações secundárias. Esta contradição ilustra de maneira exemplar a recusa freudiana em conformar sua teorização em um sistema e em sacrificar à coerência desse sistema suas descobertas clínicas. Convivendo com contradições e impasses, conseguiu manter a vitalidade de sua teoria, tornando possíveis, como se verá, as transformações operadas por autores pós-freudianos.

O aprofundamento e a articulação de uma das mais importantes descobertas freudianas, fundamentalmente a concepção do inconsciente como constituindo o psiquismo genuíno e do primado da afetividade na constituição da subjetividade, bem como o afastamento dos pressupostos paradigmáticos da modernidade e dos conceitos metapsicológicos a eles vinculados, tornaram possível elaborar uma outra perspectiva sobre o sujeito e suas relações com a sociedade. A seguir, privilegiarei a teoria elaborada pelo psicanalista inglês Donald Winnicott, no intuito de mostrar que sua concepção permite pensar a emergência da singularidade no bojo do processo de socialização, ultrapassando o pessimismo da construção freudiana.

Winnicott se afasta do essencialismo da segunda teoria pulsional freudiana, rejeitando, em conseqüência, a tese da pulsão de morte como expressão de uma natureza humana imodificável. Embora recuse o determinismo da natureza e adote uma perspectiva historicista, ou seja, mesmo considerando que o sujeito se constitui conforme a singularidade de sua experiência, Winnicott não adere à perspectiva oposta, que faz do sujeito um mero efeito do outro. Formulando o conceito de Psicosoma, como dado natural a sustentar a emergência do sujeito, o autor inglês aprofunda a concepção freudiana contida na segunda tópica ${ }^{8}$ e superando o dualismo entre corpo e psiquismo. Este conceito de psicossoma permite pensar formas básicas de apreensão de sentido e de registro de experiências que antecedem e independem da linguagem e, inclusive, das imagens.

Dotado de uma capacidade natural de imaginar - patrimônio antropológico -, o psicossoma porta em si a capacidade de criar e de se auto-criar enquanto sujeito. Esta capacidade ${ }^{9}$, assim como a motilidade e o erotismo que Winnicott atribui ao psicossoma, não constituem pressupostos metafísicos, mas formulações teóricas diretamente derivadas de uma prolongada experi- 
ência. Com efeito, Winnicott trabalhou durante várias décadas como pediatra e como psicanalista, especialmente de crianças, adquirindo uma enorme experiência. Experiência, escrevia, que lhe permitia elaborar uma hipótese cujo valor, insistia, derivava do fato de funcionarem, isto é, de permitirem lidar eficientemente com a realidade.

É importante frisar neste ponto que tanto Freud quanto Winnicott sustentaram sua elaboração teórica na experiência clínica, mas que, ao contrário do psicanalista inglês, o fundador da psicanálise elaborou tais experiências utilizando categorias teóricas que o mantinham atrelado a pressupostos deterministas e essencialistas. Assim, a constatação da onipresença da agressão na experiência clínica não fazia da formulação da pulsão de morte uma conseqüência necessária. Para dar este passo, Freud pensou aquelas experiências no contexto de pressupostos cuja pertinência não decorrem da própria experiência. A extensa experiência winnicottiana com bebês, crianças e psicóticos - experiência que faltava a Freud - permitiram ao psicanalista inglês pensar a agressão dos sujeitos como uma conseqüência possível, porém não necessária, do processo de construção e funcionamento da subjetividade. Na sua concepção, o psicossoma inicial é portador de uma série de 'tendências' que integram sua forma de ser. Tais tendências apresentam uma dinâmica espontânea que, no entanto, para sua atualização, requerem a existência de um ambiente favorável, que Winnicott costuma designar como "mãe suficientemente boa".

Antes de introduzir o exame das tendências espontâneas da "natureza humana', convém discorrer, mesmo que brevemente, sobre a utilização deste conceito. Longe de exprimir uma concepção essencialista, na qual a natureza teria uma organização redutível à lógica identitária, o pensamento winnicottiano pode ser aproximado da perspectiva que rejeita tanto essa presunção de ordem identitária, quanto a oposta, segundo a qual a natureza só pode ser pensada como caos.

Adotando-se o conceito de magma, cunhado por Castoriadis, pode se atribuir à natureza uma 'forma de ser' que, não possuindo uma ordem identitária, permite que sobre ela sejam construídas diversas ordens, porém não infinitas ordens. Este caráter finito estaria vedado pelo fato da natureza possuir uma 'forma de ser' que não se confunde com o puro caos. A apreensão dessa forma de ser, por outro lado, não pode ser objeto do pensamento lógico-racional, explicativo, mas exige colocar em ação outras modalidades de conhecimento - saberes não científicos - capazes de produzir um conhecimento descritivo e compreensivo.

A psicanálise constitui um exemplo desta forma de conhecimento. Nessa perspectiva, as velhas categorias de essência e realização de essência, que tiveram um papel tão importante para a 'naturalização' de diversas formas de opressão e dominação, são abandonadas em benefício de outra conceitua- 
lização, segundo a qual a realidade dada constitui uma realidade virtual, cuja atualização - pensada como criação - depende das vicissitudes da história.

Entre as tendências postuladas por Winnicott, convém sublinhar: a) a tendência à fusão da motilidade com o erotismo; b) a tendência à integração do sujeito; c) a tendência a sentir-se concernido pelas conseqüências de seus atos; d) a tendência à emergência espontânea de um sentimento moral. Cada uma dessas tendências requer, para sua atualização, do ambiente favorável, entendendo-se por ambiente favorável aquele que, ao invés de se impor ao sujeito, bloqueando a espontaneidade de suas tendências, lhe permite vivenciar a ilusão de onipotência e a experiência da criação.

Neste processo, o psicossoma inicial cria sua própria subjetividade, desde seu 'núcleo', como diz Winnicott. A constituição subjetiva passa, assim, pela decisiva participação do outro, participação que, convém lembrar, já tinha sido indicada por Freud ao afirmar que à emergência do narcisismo supunha acrescentar as vivências auto-eróticas - por ele consideradas dadas pela natureza - uma "nova ação psíquica".

Esta "nova ação psíquica" foi pensada pela tradição psicanalítica como uma maneira de designar a identificação primária com o outro, momento inaugural da emergência do sujeito. Em Freud, no entanto, esta intuição não foi articulada teoricamente, coexistindo em sua obra ainda aderida ao conceito de indivíduo cunhado pela modernidade.

Espontaneidade é uma palavra-chave no vocabulário winnicottiano. Ela designa precisamente a significação atribuída pelo psicanalista inglês às tendências pelas quais se exprime a dinâmica na vida. A teoria winnicottiana é 'vitalista'. Na sua perspectiva, a vida tem uma finalidade, que consiste na sua 'preservação' e 'diferenciação'. Entretanto, dizer que a vida tem uma finalidade não equivale a afirmar que ela tem um fim. A teoria winnicottiana não é determinista. Sua perspectiva é a da criação, que, todavia, só pode acontecer quando o processo vital é comandado pelo erotismo, isto é, pela inserção do sujeito num contexto social no qual ele é acolhido numa atitude hegemonizada pelo reconhecimento de sua singularidade e alteridade.

Nesse contexto, a gênese do sentimento moral - base para a posterior emergência de valores morais - é atribuída a atualização de um dinamismo espontâneo da natureza. Assim, o sentimento ético não é o resultado da introjeção de valores impostos pela sociedade, mas emerge primariamente do próprio movimento espontâneo do sujeito, quando tal processo é favorecido pela atitude do ambiente. Contudo, a introjeção de valores superegóicos impostos pela cultura não é desconsiderada por Winnicott, ao contrário, é considerada como um processo necessário e positivo.

Todavia, esta introjeção não constitui o momento inaugural da emergência do 'sentimento moral'. Na ausência da emergência espontânea desse sentimento - quando o ambiente não favorável inibe esse processo -, esses 
conteúdos são privados de uma base genuína no sujeito, tornando dominante uma tendência à subserviência. A emergência espontânea do sentimento moral exige por parte da "mãe suficientemente boa" uma atitude de amorosa receptividade. A transmissão dos 'códigos culturais' é, por sua vez, uma função educadora. Para Winnicott, a educação - sendo imprescindível - não podia substituir o amor.

O ambiente favorável a que me referi pode ser traduzido como uma capacidade do ambiente para apreender e aceitar a singularidade e diferença de cada sujeito. Gerando a confiança do sujeito emergente no ambiente, essa atitude possibilita a expansão das tendências espontâneas, permitindo a criação do que Winnicott denomina 'verdadeiro self". Este conceito não designa nenhuma essência metafísica, mas o produto da 'atividade autocriativa do sujeito'. O sujeito é considerado verdadeiro por ser produto de sua espontaneidade. Seu oposto - que Winnicott denomina 'falso self' - designa o resultado de um processo de produção da subjetividade marcado por um ambiente intrusivo que, ao invés de reconhecer a singularidade do sujeito, projeta nele seu próprio narcisismo. Sentindo-se mal acolhido, o sujeito passa a desenvolver-se de maneira responsiva, na angustiada tentativa de adaptar-se ao que lhe é exigido. Neste caso, a criatividade é sufocada. No dizer de Winnicott, o sujeito passa a desenvolver-se a partir da 'casca', isto é, adaptando-se ao ambiente, ao invés de fazê-lo desde seu "cerne", ou seja, atualizando as tendências espontâneas que fazem dele um ser singular.

Clinicamente, o sufocamento do 'verdadeiro self" é verificado na ausência ou fraqueza, no sujeito, do sentimento de existir e do sentimento de que a vida vale a pena ser vivida. O sufocamento das tendências espontâneas faz com que a fusão entre a motilidade e o erotismo perca potência, deixando a motilidade não fusionada exposta a um processo no qual a agressividade, entendida como uma força que impulsiona em direção ao outro, se transforme em agressão, que acrescenta a esse movimento o ódio gerado pela frustração. Esses casos, para Winnicott, se caracterizam pela doença em oposição à saúde. Neles vigora o cenário descrito por Freud, comandado por impulsos autodestrutivos e destrutivos e pela forte presença do sentimento de culpa. Tal estado, contudo, não exprime nenhuma essência imodificável do homem - a imodificável pulsão de destruição -, mas caracteriza uma modalidade histórica, e portanto contingente, de produção da subjetividade humana.

Como se pôde constatar, a significação que Winnicott atribui à criatividade e à história na construção da subjetividade humana não diminui a importância do papel por ele atribuído à inserção do homem na natureza, isto é, no movimento da vida. A capacidade do homem de produzir sua própria subjetividade não significa que possa fazê-lo de qualquer maneira. Se o fizer ignorando o papel central de Eros - que sustenta o acolhimento que faz o ambiente ser favorável -, incorre no risco de criar uma forma de ser e de 
sociedade que seja fonte de sofrimento, de destruição e de autodestruição para o próprio homem ${ }^{10}$.

Eros designa, tanto na teoria psicanalítica quanto no pensamento grego, uma força unificadora, de maneira que ao nomeá-lo está se introduzindo a dimensão do coletivo, do nós, da cultura, da sociedade. É precisamente porque se insere em um coletivo que o acolhe, que o sujeito se produz em sua diferença e singularidade. O conceito de indivíduo é muito pobre para pensar a complexidade desse riquíssimo processo, podendo ser substituído com vantagem pelo conceito de sujeito pensado na sua singularidade.

Ao produzir-se na sua singularidade, o sujeito emerge do coletivo, dele se diferenciando, ao mesmo tempo em que tem nele seu ambiente vital, condição imprescindível para sua emergência. Nesta perspectiva, a afirmação da 'diferença' e da 'singularidade' convive articuladamente com a 'inserção' e o pertencimento, ultrapassando o artificialismo que consiste em pensar um sujeito como um indivíduo que precede o social e nele se insere num segundo momento.

A concepção winnicottiana, elaborada a partir de sua prolongada experiência clínica, fornece uma base de sustentação muito mais sólida para a compreensão da cidadania como pertencimento, na medida em que não incorpora o conflito com a sociedade como uma fatalidade. Seria fácil tentar desacreditar o pensamento winnicottiano, caracterizando-o como representante de um otimismo ingênuo. Esta postura, entretanto, traduziria uma total incompreensão da historicidade que caracteriza o ser do homem. Muito mais fecundo parece ser o movimento teórico que vê, em perspectivas como a formulada por Winnicott, o fruto de um trabalho que, ao romper a camisa de força dos pressupostos do paradigma moderno, permite pensar o que, sem essa ruptura, seria impossível de ser pensado. Lembrando Edgard Morin: todo paradigma organiza o pensamento, mas também o limita.

\section{Notas}

${ }^{1}$ Professor do Instituto de Medicina Social da UERJ e da PUC-Rio. Psicanalista. Notório Saber em Ciência Política.<cap@cetroin.com.br>.

2 Utilizo aqui o conceito de paradigma no sentido elaborado por Edgard Morin, a saber o conjunto de pressupostos ontológicos, epistemológicos e antropológicos que organizam e ao mesmo tempo limitam o pensamento. Para um maior desenvolvimento deste tema, ver $\mathrm{O}$ primado da afetividade: a crítica freudiana ao paradigma da modernidade (Plastino, 2001).

3 Creio que esta concepção se harmoniza com o que Geisler 'denomina cidadania por pertencimento'. 
${ }^{4}$ A experiência que nutre o conhecimento produzido pela psicanálise se caracteriza como uma relação intersubjetiva atravessada por afetos (resistência, transferência e contratransferência), diferenciando-se assim do experimento científico e do conhecimento racional. Isso faz da psicanálise um saber compreensivo e descritivo, ao invés de explicativo. Discuto esta questão e suas múltiplas conseqüências em Plastino (2001).

${ }^{5}$ Entende-se por metapsicologia a superestrutura teórica elaborada e modificada diversas vezes a partir da experiência clínica. Experiência esta que detêm a prioridade na hierarquia epistemológica da psicanálise.

${ }^{6}$ Freud denomina as pulsões de morte e de vida de bloco da natureza imodificável na nossa constituição psíquica.

${ }^{7}$ Pensada como um aspecto de uma realidade cósmica, a ambivalência afetiva postulada por Freud adquire uma característica metafísica e essencialista.

8 Na segunda tópica, formulada por Freud no artigo "O ego e o id" (1923), o psicanalista elabora uma concepção do psiquismo constituído por um inconsciente originário (o id), enraizado no corpo e, posteriormente, diferenciado num ego e num superego, construídos no contato com a cultura.

9 Capacidade que Cornelius Castoriadis denominava de "imaginário radical", capacidade humana que a "filosofia herdada", como gostava de dizer o pensador greco-francês, não podia admitir, por colidir frontalmente com seu essencialismo e seu determinismo.

10 Como parece ser o caso da sociedade contemporânea, hegemoneizada por um imaginário centrado no conflito e por práticas predatórias. 